\title{
Forgiving as emotional distancing
}

\author{
Santiago Amaya \\ Universidad de los Andes \\ samaya@uniandes.edu.co
}

There seems to be something puzzling about forgiveness. ${ }^{1}$ Forgiving someone, on the one hand, seems to involve a change of how one feels about that person for something that she did (or maybe for the way that she is). One lets go of certain feelings: resentment, anger or disappointment. Yet, forgiving also seems to require a firm judgment of culpability. If I let my feelings go because I come to believe that you didn't wrong me, then it doesn't seem that I have forgiven you. Maybe I've excused you or I've merely come to terms with what happened. So, how is forgiveness possible? How can there be a change of heart without a corresponding change in judgment?

There are several ways out of this. Many theorists, however, have insisted that genuine forgiveness requires some change in judgment. Although I might continue to view you as culpable, if I've truly forgiven you, I must have ceased to judge that you are a threat, that you disregard what matters to me, or that your action is representative of who you are deep down. Put more positively, I must have come to view differently the significance of your action with respect to who you are or must have come to the conclusion that some of the attitudes behind it have changed in a favorable way. ${ }^{2}$

Sometimes, no doubt, this description is apt. We come to judge people differently and that gives us a reason to forgive them. Yet, as I discuss in this paper, a change in judgment is not required for genuine forgiveness. Forgiving, as we shall see, is primarily a change in emotion. The emotions in question are warranted responses to appraisals of culpable wrongdoing. Yet, forgiving is possible and often rational because it is a form of emotional distancing.

' Different ways of stating the puzzle can be found in Kolnai (1973), Hieronymi (2001: 529-530), Griswold (2007: ch 2), Zaibert (2009), Warmke and McKenna (2013: 207-208), Nelkin (2013), Gormley (2014)

2See, for instance, Hampton (1988: 83-85), Hieronymi (2001), and Allais (2008) 
I begin by sketching a model of what emotional distancing is and how it applies to acts of forgiveness. Then, I introduce and defend two ideas that are key to it. The first is that emotional distancing is a process of motivational change. The second is that, by virtue of the emotions involved in it, forgiving is primarily a social affair. Put together, these ideas help explain why forgiving someone might be a rational thing, even when it is not preceded by a change in how the wrongdoing or the wrongdoer are judged. In the end, some attractive consequences of the model are discussed.

\section{Distancing}

Emotional distancing is a general phenomenon, not restricted to forgiveness. We can understand it as the process by which one's emotions towards a remembered event, or set of events, gradually disappear and eventually become replaced by a memory of one's emotional response to the event. Clearly, it is not an episode of forgetting. In many cases, in fact, one distinctly remembers the emotions once felt. But, being a change in how one feels, it does signify a change in some of one's behavioral and cognitive dispositions.

The phenomenon is common in everyday life. As I've grown older, for instance, I've become somewhat distant from my best friend in high school. I still see him with relative frequency. I continue to judge that he is a fine man, someone fun to hang out with, etc. In fact, I am still very fond of him. But, I certainly don't feel towards the things we did together the way I did twenty-something years ago. I've distanced myself emotionally from those memories. Similarly, I used to regret some of the choices I made when I was in graduate school. I continue to think many of them were poor, even regrettable, choices. But the feeling of regret that I used to have when I thought about them is now, fortunately, gone. Still, I vividly remember the feelings that used to haunt me then.

Forgiving, as I understand it, is a form of emotional distancing. When one forgives a person for having done something wrong one takes distance from the blaming emotions previously developed as a response to the wrongdoing. One does not forget the wrongdoing, or how one felt about it. One does not cease to believe either that the person did wrong or that one had reason to feel as one did. 
Still, as one forgives, the emotional aspect involved in thinking about the episode (the anger, resentment, etc.) changes in significant respects.

Emotional distancing, it should be noted, does not imply personal distancing. Forgiving someone, precisely because it involves leaving behind one's blaming emotions, often results in one becoming closer to the person. It does not imply either indifference about what happened. Taking distance from those emotions is compatible with having other feelings (chagrin, disgust) towards the episode of wrongdoing. Lastly, emotional distance does not imply thinking differently about the episode, even though it does change the way the thought of it configures one's emotional state.

Schematically, we can represent the transition constitutive of forgiveness as follows. Let e stand for any past event that might qualify as an episode of wrongdoing: an action or an omission. Let $\mathrm{M}(\mathrm{e})$ stand for one's memory of an event. And let $\mathrm{E}_{\mathrm{s}}(\mathrm{e})$ represent one's emotional blame-response towards an event. Then, understood as a process of distancing, forgiving can be characterized in terms of this schema:

$[\mathrm{F}] \quad \mathrm{E}_{\mathrm{s}}(\mathrm{M}(\mathrm{e})) \Rightarrow \mathrm{M}\left(\mathrm{E}_{\mathrm{s}}(\mathrm{e})\right)$.

Emotional distancing in general is made possible because emotions are attitudes with distinctive characteristics. One of them is that emotions are not, as perhaps beliefs are, punctuated occurrences. Rather, they tend to have a dynamic temporal profile, which allows some of their characteristics to change over time. Thus, in the afternoon, you might continue to be annoyed by the fact that in the morning you locked the car with the keys inside. But perhaps you do not feel anymore like kicking the car's door in anger. With time, you have somewhat distanced yourself from what you initially felt.

What is true about anger holds as well about distinctive moral emotions, such as resentment. They too occur and change in time. With respect to the blaming emotions, however, it is not so much their temporal but their social dimension what makes forgiveness possible and interesting in relation to our moral lives. At least, this is what I argue below. Because moral emotions are inherently social, they are modulated by changes in the social environments we normally 
navigate, not just modulated by the judgments we make. In particular, they are rationally attuned to the emotions and intentions of the people with whom we normally interact.

Before I get into this, let me bring to the fore some background. Emotional theories of forgiveness tend to go hand in hand with emotional accounts of moral blame. ${ }^{3}$ If to blame someone is to develop certain emotions towards her, then it does seem that forgiving is a process of emotional change. To me, this looks like a very compelling argument in favor of developing a proposal of the sort sketched here. But this line will not be pressed below. I won't argue for the conditional or defend the antecedent.

Yet, even if blaming is not always an emotional response, I think there is good reason for thinking that forgiving is primarily an emotional affair. ${ }^{4}$ Not only does it accord with common phenomenology and ordinary ways of speaking. Also, putative examples of non-emotional acts of forgiveness tend to look hollow. Either they seem hypocritical: the person says the words "I forgive you" but does not mean what she says. Or they seem honest acts of trying to get back to some state of affairs prior to the wrongdoing, but still short of being acts of forgiveness. Forgiving, after all, is only one way of making amends.

\section{Emotions}

Forgiving, as I just claimed, is taking distance from one's initial blaming responses to an episode of wrongdoing. Taking distance is an emotional change. As one forgives, one ceases to feel, say, resentment about something that was done to one.

${ }^{3}$ Examples of emotional accounts of blame can be found in Strawson 1982, Wallace 1994, Wolff 2011, McKenna 2012, Bennett 2003.

"One possible way to express the claim here is that the term "forgiveness" exhibits the kind of homonymy that Aristotle thought was characteristic of many theoretical terms. On that reading, emotional distancing would provide the term with what G.E.L. Owen (1960) called a "focal meaning," by reference of which other akin process of reconciliation would derivatively count as acts of forgiveness. I thank Fred Miller for suggesting this way of putting it. 
In turn, changing one's emotional state leads to changes in the way one goes about and treats the wrongdoer. Letting go of one's resentment, for instance, one ceases to try to get back at the person, or to wish that she suffered for what she did.

To make this clear, it is worth thinking a bit about the nature of emotions. Indeed, standing theories of forgiveness often say little (and presuppose a lot) of what emotions are. As I understand them, emotions are psychological attitudes functionally defined in terms of some general dispositions. Obviously, I cannot provide a full analysis here. But, short of providing it, a useful way of getting at their functional role is to ask what distinguishes any given emotion from another. What, for instance, marks the difference between anger and fear, regret and guilt, and so forth?

A starting point is that affect, understood as a function of valence and arousal, is not a general criterion for distinguishing among emotions. Whereas feeling happy and depressed are clearly different in both dimensions, these do not help distinguish the members of other emotion-pairs, say, feeling disappointed and feeling humiliated. Both of them have negative valence-it is evidently unpleasant to feel either. And both emotions are characteristically low in terms of arousalhaving either feeling hardly energizes one in the way in which, say, anger or fear energizes one.

A better candidate for marking the distinction comes from the idea that emotions involve distinct cognitive appraisals (Lazarus 1991; Nussbaum 1997). Among emotion theorists there are long-standing debates about the content of these cognitions. We can think of an appraisal though as an evaluation of the object of the emotion, clustered around a core relational theme. Becoming afraid of something, thus, involves appraising that thing as a danger to oneself. Becoming angry at it involves appraising it as an obstacle to attaining one's goals or to one's enjoyment of a desirable state of affairs.

Recalcitrant emotions, however, show that this can't be the full story (D'Arms \& Jacobson 2003; Grzankowski 2017). These cases seem best described as episodes of irrationality that involve a person having a certain emotion but lacking the corresponding appraisal. Fear of flying is a common example: people who suffer it often recognize there is little danger involved in doing it. Survivor's guilt is, perhaps, a more suitable illustration for present purposes. The person knows that 
she didn't do wrong but feels guilty about having survived the tragic event to which others succumbed.

It might possible to re-conceptualize recalcitrant emotions so that they come out as compatible with cognitive theories. For instance, they can be described as cases of a person having a certain emotional appraisal and explicitly holding some attitude (say, a judgment) contrary to it. The problem with such re-descriptions is that they make unclear what kind of cognitive attitude an appraisal is. In doing so, they make the phenomenon of recalcitrance even more puzzling.

Suppose, for example, that appraisals are attitudes of assenting to some content. In that case, recalcitrance would seem to involve an outright contradiction. That, however, seems too strong. Survivor's guilt might be irrational but it certainly isn't unintelligible. On the other hand, if appraising is not assenting, then it is unclear why recalcitrance counts a form of irrationality. Consider other nonassenting cognitive attitudes. There is nothing wrong with imagining or merely supposing things being contrary to what one judges to be the case.

Motivational approaches to emotions fare better on these fronts. ${ }^{5}$ According to them, what makes emotions what they are is that they dispose one to pursue distinct kinds of goals and to structure their pursuit in particular manners. Which is just another way of saying that emotions have a characteristic motivational role, defined around abstract patterns of behavior and thinking (Frijda 2008; Scarantino 2014). This explains why emotional states that are similar in affect can nevertheless be of a different kind: each motivates different behaviors. It also helps make sense of recalcitrant emotions as instances of practical, as opposed to a kind of cognitive, irrationality. What is problematic about recalcitrance, as in other similar cases, is that what motivates one to act fails to cohere with one's reflective attitudes about the grounds of one's motivation.

${ }^{5}$ Obviously, this is far from being a knockdown argument on behalf of the motivational theories of emotions. Also, it should be noted that affect and cognitive theories are not the only theories on offer. For a recent development of a perceptual theory designed to overcome these pitfalls, see Tappolet (2016). Helm (2011) develops a theory that dispenses with the distinction between the cognitive and the motivational as presupposed here. 
In the case of emotions, their motivational role comprises several elements. First, by feeling a given emotion one becomes disposed to behave in certain goaloriented, even intentional, ways. Being afraid of something, for instance, normally disposes one to avoid it; being angry at it disposes one to be aggressive towards it. Second, being disposed in these ways tends to tend have a certain urgency. That is, even if I wind up not avoiding or engaging with whatever scares or angers me, behaving otherwise typically takes some amount of self-regulation in the form of actual effort or prior training. Finally, the motivational role not only extends directly to one's overt behavior, but also to certain kinds of thoughts and expectations. As we shall see, thinking about these expectations will be of importance for understand why forgiving can be rational even without a change in judgment.

No doubt, some theorists would object to the generality of this approach. ${ }^{6}$ Some emotions, for instance, admiring a beautiful landscape, seem purely contemplative. Others, say, intense grief, might dampen motivation, or even leave you completely lacking in it. These are hard cases but fortunately we do not need to worry about them here. For whereas some aesthetic emotions might be motivationally inert and some emotionally overwhelming events might make you numb, blaming emotions are not like this. To resent someone, to feel angry at her, to be disappointed at what she did, in so far as they embody attitudes of blame, make sense only to the extent that they motivate one in some way or another.

With this in mind, we can now say more precisely what emotional distancing is and how the process is, at least in principle, possible. In essence, when one distances oneself from some felt emotion one ceases to be in the motivational state in which one otherwise was. Because of it one ceases to be disposed to behave in

-I thank David Shoemaker for pressing me to address this point.

'Dorothea Debus (2007) is skeptical about the possibility of emotional distancing as characterized here. For her, autobiographically remembering an emotional event is itself a new emotional experience, where new and remembered emotions normally coincide. Debus does not exactly say how she thinks about emotions. Her argument works, I suspect, precisely because it presupposes a view of emotions as reducible to affectively-laden judgments. 
relation to the object of the emotion in the way one used to be. On revises some of one's goals, or comes to prioritize them differently. Yet, the change can happen independently of there being any affective alteration in oneself or in how one thinks about the object. The motivational change, in other words, need not require a change in affect or appraisal.

Applied to our present concern, this general model yields the proposed account of forgiveness. When one forgives, one gains distance from a blaming emotion in the sense that one ceases to be in the motivational state characteristic of that emotion. That is, one acquires a general disposition to behave differently, in the relevant respects, towards the person that one used to blame. This need not mean a change in affect. One can still feel pained by the person or what she did, feel uncomfortable in her presence, or simply feel bad about the whole thing. None of that is incompatible with forgiving. Nor does the distancing need to be accompanied by a change in how the person or what she did gets appraised. One might forgive and still think she is responsible for the wrongdoing, that she is a bad person, that she displayed ill-will towards you, etc.

Obviously not all forms of distancing count as forgiving. Sometimes, as with the car keys example mentioned earlier, one's blaming emotions simply dissipate over time. And, although I am skeptical of there being necessary and sufficient conditions here, it is fair to say that mere dissipation is not a form of forgiving. Below some of the ways in which forgiving can actually happen will be discussed in some detail. Before getting into them, however, there is one more thing that needs to be said first.

\section{Sociality}

Emotional distancing, as I see it, is primarily a change in motivation. A change of this sort, however, might appear to be too private of a phenomenon to serve as an

\footnotetext{
s There is indeed evidence that lay concepts of forgiveness have what seems like a prototype structure (Kearns \& Fincham 2004, Lawler-Row et al 2007). If this is true, then no analysis of forgiveness in terms of sufficient and necessary conditions can simultaneously respect folk intuitions across the board.
} 
account of forgiveness. That is, whereas forgiving without a corresponding emotional change might be hollow, it would seem that what should be central in an account of forgiveness is the interpersonal, social nature of the act. Without the latter, forgiving would be akin to promising without ever saying the words."

I believe there is a grain of truth behind this criticism: forgiveness is eminently a social affair. But, aimed at the present account, the criticism rests on a mistaken idea of what is involved in emotional distancing. Importantly, seeing why there is a mistake here might prove actually helpful for the present argument. In short, if one views forgiveness as a change internal to the person, then one might be led to look for the reasons of that change within the person herself. And once one makes this move, it is tempting to think that the reason for the change must lie in the person's judgment. This, I think, is not true.

Consider, then, a version of the criticism due to Brandon Warmke and Michael McKenna (2013: 198-201). According to them, blaming can be done privately or overtly. The former involves adopting a blaming attitude without behaviorally manifesting it; the latter involves its manifestation. Similarly, they claim, one can forgive privately or overtly. Forgiving privately amounts to the overcoming of a blaming emotion (resentment, for example), whereas overtly forgiving amounts to communicating in a socially visible manner that one no longer will treat the wrongdoer in certain ways.

Warmke and McKenna argue that, in offering an account of forgiveness, overt episodes should be taken as paradigmatic. In a nutshell, this comports better with the intuition, which I share, that forgiving others is important because of the changes it brings about in our communal life. Private forgiveness, on their view, while possible, is a somewhat marginal phenomenon. Thus, they recommend dispensing with views that stress overcoming the blaming emotions and suggest,

- Theorists have drawn the contrast intended here in different ways (see, Baumeister et al 1998; Adams 1991: 294; Zaibert 2009; Warmke \& McKenna 2011). For present purposes, these differences do no matter. The argument of this section is aimed at showing that, even understood as a process of emotional distancing, forgiveness is best understood as an intersubjective/public/social happening. 
instead, a behavioral account where overcoming the emotions need not be presupposed.

We can agree with them that there is something marginal about private episodes of forgiveness. Privately forgiving someone, very much like privately blaming them, tends to mark a breakdown in sociality. Sometimes it even seems unhealthy: if I privately forgive you but let you go on repenting, something seems to be amiss in me or in our relation. But we need to resist, I believe, the assumption that runs through out Warmke and McKenna's criticism and that, non-incidentally, many theorists who defend an emotional account seem to tacitly share: namely, that overcoming a blaming emotion is a private event.

Recall our earlier discussion. Suppose you think that emotions are affects. Then, overcoming an emotion is surely something private. At the very least, it amounts to ceasing to have experiences defined by properties (valence, especially) that can only be grasped introspectively-or by interoception, if one thinks that affects/emotions are markers of somatic states. ${ }^{.0}$ Likewise, suppose you think that emotions are appraisals. Then, there might be reasons for thinking that overcoming an emotion is a private act. For one thing, an appraisal is conceptually separable from its behavioral manifestation. However, once you think of a given emotion as essentially motivational, as I recommended above, you become open to the possibility of viewing emotional changes as public or social events.

The point applies generally (although perhaps not without exception) to the kind of emotions, of which the blaming ones are a subset: the so-called Strawsonian reactive attitudes. Just to take a positive example this time, consider gratitude. Coming to feel gratitude is certainly pleasant. No doubt it involves coming to have some positive thoughts about the person to whom one feels it, for instance, that she voluntarily did something costly that benefitted one. Yet, it is hard to imagine what gratitude would be like if it were not to involve some sort of disposition to be nice towards the person to whom one is grateful, to reciprocate the favor, etc. In fact, developing feelings of gratitude seems to matter within the context of our moral life precisely because they are significant contributors to

${ }^{10}$ Two examples of this view of emotions can be found in Damasio (1999) and to a large degree Prinz (2004). 
helping and other pro-social behaviors (McCullough et al 2001, Bartlett \& DeSteno 2006).

The same holds, even more perspicuously, with respect to the emotions of blame. Blame, being a practice whose purpose is the coordination of communal life, presumably makes the emotions implicated in it social." Part of what this means is that the functional role of these emotions is largely defined in terms of socially relevant and meaningful behaviors. Which means that coming to feel these emotions amounts to acquiring dispositions to engage with others in ways that shape communal life. Importantly for present purposes, these behaviors are not, as Warmke and McKenna put it, "criterial indicators of what would count as an expression of that emotion" (2013: 199. My emphasis). They are instead the essence, the what-it-is-to-be, of the emotion itself.

Let me explain. There is an obvious sense in which emotional changes are events that happen within a person. For one thing, by virtue of being psychological changes, they tend to have the intimating aspects that some events in our mind tend to have. There is, on other hand, another obvious sense in which changes in one's internal motivations can be socially relevant. They dispose one to intervene in the external world. There is, however, a deeper sense in which blaming emotions are more than psychological dispositions that happen to be manifested in socially relevant ways. They are, in brief, dispositions whose point is the regulation of social life.

As a useful comparison, think about other non-emotional, yet eminently social dispositions, such as being kind or being mean. Whereas there is no unique behavior that defines these dispositions, manifesting them is normally a matter of behaving in certain ways towards others. You can certainly be a mean person stranded in a desert island. But by calling you "mean," the expectation is that you would behave in certain ways if the island were instead populated. Equally

\footnotetext{
"What I say here follows from recent communicative accounts of blame. For an in depth discussion of the idea that blame is essentially communicative, see McKenna (2012), Macnamara (2015), and Fricker (2016). David Shoemaker and Manuel Vargas (forthcoming) develop a signaling theory of blame, where these points are discussed in more detail.
} 
important, the significance of these dispositions tends to be defined in relation to their social manifestation. Being kind only in private, if that thing exists, doesn't really score you any points.

Something similar happens with respect to the blaming emotions. Although they can privately be felt, they tend to have other people as their intended audience. Perhaps, lying alone in bed you might come to resent the colleague who earlier made a snarky remark about you. If you are like me, however, your resentment will trigger in your mind a conversation with your colleague-only that this time you come up with the perfect line in response to her remark. In addition, whatever good there is in feeling these emotions, it is often connected to their social manifestation and the possibility of their uptake. Thus, if something positive is to come out of being angry at your colleague, is that, if you voice your concerns, you two can start a conversation about how to improve things.

This is not to say that one cannot withhold these social behaviors, while feeling the corresponding emotions. If one had a reason, one could try to do it and succeed at it, as when one reigns in the temptation of thinking about taking revenge in order to avoid actually doing it. Nor is it to deny that experiencing privately these emotions can be good. I might certainly feel angry for things that nobody knows about and, perhaps, it is best for me to keep it that way. Nevertheless what's basic about them is their public and social nature. What's derivative, sometimes deviant, and often in need of explanation, is their remaining bottled inside.

The same, I'd say, is true about forgiveness. As Warmke and McKenna put it, paradigmatic instances of forgiving are public, not private. But this in no way creates a problem for the present account. It is precisely the opposite. Socially visible forgiving is paradigmatic because forgiving is a form of emotional distancing and the emotions in question are by their very nature social. By forgiving, in other words, we change how we feel, but to change how we feel is to change our social dispositions towards those we used to blame. Sometimes we try to get close again, we cease avoiding them, we stop frowning, etc. Only in very specific cases is emotional distancing a private affair, say, when I forgive but decide to conceal it for strategic reasons. Unsurprisingly, it is precisely those cases that require some additional explaining. 


\section{Trajectories}

Although forgiveness is primarily a change in heart, sometimes the change is made possible by a revision in judgment. Certainly, you do not change your mind about the person's actions being wrong or her being accountable for them. That, again, would be to excuse or condone what she did. But, with time, you come to judge her differently as a person. You come to see her as morally transformed (Hampton 1988: 83-85). You learn not to judge who she is on the basis of her worse choices (Allais 2008). Or, simply, her actions cease to signify that the person is a threat to you (Hieronymi 2001).

Among others, Pamela Hieronymi has argued that these possibilities point towards a stronger requirement. On her view, genuine forgiveness must involve some kind of revision in judgment (2001: 530). Accordingly, she claims that an emotional account of forgiveness, such as the one I am recommending here, ought to be articulate. That is, it should make distancing the consequence of the fact that one's emotions change by undergoing rational revision. Otherwise, it risks making forgiveness an instance of emotional manipulation or something that merely happens beyond one's control.

We can agree that an account of forgiveness ought to be, as Hieronymi puts it, articulate. Whereas one might not forgive at will, forgiving seems to be under one's rational control. This, however, should not commit us to view emotional distancing, as she argues, as a response to a change in judgment. Surely, changes in judgment can provide a reason for revising how one feels about something. But one's emotions can rationally change in all sorts of ways, which are not necessarily or even best explained by a change in judgment. In other words, because emotions have some particular dynamics, there are many things that can rationally alter how one feels, on account of which a change in emotion can count as a process of rational revision.

Begin with a few non-moral examples. If I intend to get early to the office,

rush hour traffic might frustrate me. I might get rid of the frustration by reevaluating how bad the traffic really is. But there are other ways of doing it. For instance, if I revise my intention to arrive early, I might have a reason no to be 
frustrated by traffic anymore. Similarly, wanting to impress my guests might make me anxious about my abilities as a cook. If I reconsider my desire to impress them, however, that would give me reason to stop being anxious, even if I continue to judge that cooking is not really my thing. In fact, not only can changes in intentions and desires become reasons for changing how one feels about something. Emotional changes too can rationally produce further changes in emotions. Sometimes, for instance, getting rid of one's fears feels like a relief.

The same holds with respect to our blaming emotions. Motivation, as it is often said, is holistically shaped. Hence, to the extent that these emotions play a motivational role, they too can be rationally shaped by other attitudes that motivate us to act. With time, for instance, many of one's emotional attachments change. And, because of that, one often ceases to feel hurt or disappointed by others, despite continuing to believe that they did wrong, that they showed a lack of proper regard, etc. Simply, they are no longer close enough for some of those feelings to make sense. Likewise, changes in desires and intentions can bring about a change in one's blaming emotions. Resentment towards someone might dissipate if, say, one forms the intention not to be part of circle of revenge.

These cases are likely not good examples of forgiving - the reasons do not seem to be of the right sort. Yet, once these possibilities are in, one can see how emotional distancing might be both rational, not the product of a change in judgment, and yet count as an instance of forgiving. Recall the idea, discussed above, that blaming emotions are eminently social. There, I emphasized one aspect of it: namely, that they motivate one to act in socially meaningful ways. There is, however, another equally important aspect of this idea. This is that unlike many other moral emotions, the emotions behind blame are normally embedded in trajectories of social exchange. Briefly put, they dispose one to expect certain responses from others and to react to those responses in particular ways. As a consequence, they normally occur within distinctively social patterns. ${ }^{12}$

${ }_{12}$ The idea of blaming and forgiving as occurring in trajectories of social exchange is inspired by Victoria McGeer (2010), who talks about blaming attitudes as essentially occurring in patterns of co-reactivity. 
Think, by way of contrast, about bitterness. As it is often defined, bitterness seems a candidate for a moral emotion. It is a response to a treatment perceived as unjust (Linden et al 2007; Znoj 2011). Yet, unlike resentment, which is too a response to a perceived injustice, episodes of bitterness tend not to be embedded in a social exchange. Embitterment is normally accompanied by a sense of helplessness. Which means that the bitter person not only tends not to address the source of the injustice, say, the boss who would not recognize with a promotion her efforts at work. She also does not expect that source to respond in any particular way to her bitterness. As theorists often put it, the bitter person is characteristically low in coping potential.

Things are different with the core blaming emotions. Normally, they dispose us to address those who have wronged us in a variety of ways. If I resent you, I might be tempted to respond with an insult. If you hurt my feelings, I might request an explanation. In addition, they dispose us to expect certain kinds of responses to those addresses and to react in certain ways to the responses they generate. In other words, we expect our blaming emotions to have a certain kind of uptake. Among the possibilities, we tend to expect the person to respond by revising her intentions and by feeling in certain ways.

It is in this respect that blaming emotions can be overcome in a rational way to count as forgiveness. To the extent that blaming involves expecting certain responses, those responses can potentially become reasons to change one's emotional state. By being indifferent towards my hurt feelings, you might give me a reason to resent you. If, on the other hand, you genuinely feel bad about hurting my feelings, that might become a reason to forgive you. Likewise, depending on the particular case, your feeling guilty, your resolve not to wrong me again, your desire that things had been different, etc., are potentially, in and of themselves, reasons to forgive you.

The point can be put in slight different way. As I argued above, as far as the blaming emotions go, emotional distancing is normally a social event. Part of this has to do with the fact that these emotions motivate socially meaningful behaviors. But an equally important part of it is that the emotions take place in a communicative context. Not only does the expression of my resentment come with certain expectations as to how you will react to it. Also your falling in line or not 
with those expectations might provide the better reasons to cease resenting you. That is, what often justifies a change of heart on my part, what makes it intelligible, is the way you respond to the emotions of blame I developed because of your wrongdoing.

Put in this light, the requirement that to count as rational forgiveness ought to involve a change in judgment seems misplaced. Of course, if I judge that you do not care about me, or that your are still a threat to my moral dignity, it might be somewhat inconsistent to forgive you. But episodes of blaming need not involve this kind of judgment. ${ }^{13}$ Plus, inconsistencies can always be rationally resolved in either of two ways. Which seems to indicate that forgiving the wrongdoer, while it might be a response to a change in judgment, need not be such for it to be a rational change. In fact, sometimes it happens the other way around. One comes to judge that a person's attitudes have changed in relevant ways, that she has been morally transformed, etc., only because of the gratitude and appreciation she shows after being forgiven.

What emerges, then, is a picture of emotional distancing that is rational and yet not cognitivist. This is the possibility that Hieronymi, and others who make similar demands, seem to miss. Furthermore, the picture is both motivational and social in nature. In general, blaming emotions bear rational interpersonal connections to the motivational states of those who we address with them, which means that we can rationally change in direct response to their motivational or other affective states. It is here that the possibility lies of forgiving without a prior change in judgment.

I now turn to discuss some attractive consequences of the present proposal.

\section{Pluralism}

${ }^{13}$ These judgments would seem to describe best what happens in contexts of relationship breakdown: the partner who ceased to care, the friend who systematically mistreats you might merit this kind of evaluation. Yet, to the extent that plenty of blame and forgiveness happens within healthy and good relationships forming these judgments does not seem necessary for blame; revising them does not seem necessary for forgiveness either. 
To forgive, according to a common line, is to overcome resentment. Perhaps, this is the favorite way for emotion theorists to define forgiveness. And it would count as a formidable agreement, if it were not for the fact that those who hold it tend to adopt very different views about what resentment is. For some theorists, it is a hostile vindictive sentiment (Murphy 2012: 31; Garrard \& McNaughton 2002: 44). Others take it to be a form of anger, which does not necessarily involve motivation to retaliate (Holmgren 2012). Yet, others view it as a form of emotional protest that seeks to affirm the wrongness of the act and the moral significance of the victim (Hieronymi 2001).

A theory of forgiveness, in my opinion, should recognize from the outset that there are many of ways of blaming. Hence, it should not define forgiveness around one specific emotion. This is implicitly recognized in our schema $[\mathrm{F}]$ and in our discussion up to this point. Whatever blaming emotions one develops in response to being wronged, forgiving the wrongdoer is a matter of taking distance from those emotions. As with blaming, there are also many ways of forgiving.

To be sure, some wrongdoings seem to warrant hostility and, thus, forgiving their perpetrators involves overcoming the desire of getting back at them. But many wrongdoings are not like this. My parents' failure to call my son for his birthday reasonably might hurt my feelings. I might blame them for it, expect them to apologize, and decide not take the initiative to plan their next visit. But the thought of punishing them for it will likely not cross my mind. Perhaps, if it were part of larger pattern of neglect, I would protest their oversight. I would even remind them of the moral worthiness of my child. Yet, given the way things are with them that would be overly dramatic.

Now, this should not be read as a criticism of the accounts of resentment mentioned above. Our emotional vocabulary tends to be limited, so it would be a surprise if common usage of "resentment" were to pick a single well-defined emotion. What I am saying is that blaming responses can vary widely in terms of their motivational role, which means that distancing from them can take various forms. Sometimes it involves distancing from resentment. Other times it involves contempt, disappointment, or hurt feelings, so far as these too can be considered blaming emotions. 
This kind of pluralism has several advantages. The first, perhaps the most salient one, is that it can respond in a principled way to standard objections raised to resentment-focused accounts (Nelkin 2013; Warmke \& McKenna 2013). Because resentment is one among many blaming emotions, overcoming it need not be necessary or sufficient for forgiving. Also, to the extent that these emotions differ in their motivational role, the account helps to understand why we should not expect to find a single behavioral script for forgiveness and why factors other than those internal to the wrongdoing modulate instances of forgiving. Importantly, to the extent these emotions differ from each other, they will dispose us to expect different reactions from those addressed with them.

Consider anger and disappointment. Although there are non-moral variants of them, some of their episodes are good candidates for blaming emotions. Anger and disappointment feel bad; both of them are reasonable responses to blameworthy acts; both signal a commitment to certain moral standards. However, each emotion seems appropriate with respect to a different range of situations. It would seem odd, for instance, to feel disappointed at the wrongdoings of a complete stranger. By contrast, it would seem too detached to feel mere disappointment, not anger, in relation to a heinous crime. What's more, in each case, the warrant extends to different kinds of behavior. Anger preponderantly leads to aggressiveness; disappointment leads to withdrawal.

It follows from this that we should not expect to a find a unique behavioral marker of forgiveness, even abstractly formulated. And, in fact, this is what we actually observe. Some people forgive by ceasing to be aggressive; others forgive by trying to re-approach. In general, what we find is that the many ways of forgiving are not just a function of the nature of the offense: the amount of wrongness, the degree of responsibility, etc. They are also a function of the relation one holds to the offender, the quality of that relation, etc. (Fincham 2000, McCullough et al 2001). They are, in other words, a function of the same kind of factors that make some blaming emotions appropriate and other inappropriate. By making pluralism about forgiving depend on pluralism about blame, the present account nicely explains this correlation.

Similarly, to the extent that anger and disappointment differ from each other, it is reasonable that each come with different expectations. This means that 
depending on the case different kinds of responses from the wrongdoer might be good reasons to forgive her. My anger towards you might come with an expectation that you compensate me for what you did. If you do it, that could be a good enough reason to forgive you. On the contrary, if what I feel towards you is disappointment, your doing nice things for me might strike me instead as a silly pleasantry. What I want in order to forgive you is that you show me that I can trust you again.

A further advantage worth remarking is this. By focusing on resentment various emotion theorists have wound up in a position that should look, at this point, a bit awkward. Because resentment is characteristically a second-person emotion, they have problems accommodating forgiving in the first and third person cases. Charles Griswold's (2007) account provides a nice illustration. For him, forgiving oneself or forgiving someone for the harm done to somebody else are "imperfect" forms of forgiving. Unlike acts of merely excusing or condoning, they cross a threshold to be considered instances of forgiveness. Yet, because they fall short of meeting some "paradigmatic" conditions, they seem to be lacking in some important respect.

The argument certainly has an air of circularity. First and third person forgiveness are surely imperfect relative to a paradigm of forgiveness, which, as in Griswold's account, gets defined by the appropriateness conditions of the second person case. In his defense, Griswold adds that even in the first and third person cases meeting those conditions is desirable, even if impossible. I don't think that this is true, as it will become clear below when we discuss the conditions of forgiving. For the moment, however, the point that needs to be made is this. If one accepts the kind of pluralism embodied in schema $[\mathrm{F}]$, the problem of accommodating cases of first and third person forgiveness goes away. In brief, if there are first and third person blaming emotions, which there are (guilt and indignation, respectively), there is too the distancing from those emotions. If distancing is possible, there is nothing preventing, at least in principle, fullblooded cases of forgiveness in the first and third person.

\section{Conditions}


Forgiving involves revising one's emotions in the light of the wrongdoer's responses to one's blame. It would seem natural to argue from here that the rationality of forgiveness depends upon certain necessary conditions being met. The idea is central to conditional accounts of forgiveness, which insist that people ought not to forgive unless the offender has gone certain specific processes: repentance, atonement, etc. (Murphy \& Hampton 1988; Haber 1991; Griswold 2007: ch. 2). As Jeffrey Murphy puts it, forgiving in violation of some of these conditions signals a lack of self-respect (Murphy \& Hampton 1988: ch. 1)

These kinds of generalizations strike me as problematic. Fortunately, there is reason for being skeptical about them. Inductively speaking, most attempts to turn a good reason for forgiving into a condition of it have proven problematic. Advocates of uncompromising forgiveness have provided very persuasive examples of this (Garrard \& McNaughton 2002; Allais 2008; Norlock 2008: 83-91). Whereas in some cases receiving an apology is good enough to forgive, there are cases in which the apology seems not enough and cases where it does not seem necessary. The same happens with punishment, atonement, and other prima facie plausible candidates.

Now, some theorists have taken the impossibility of finding generalizable conditions as evidence that forgiveness is not a unified notion (Bennett 2003 and Fricker forthcoming). But I think there are better explanations for it that do not result in a disjunctive treatment of forgiveness. One of them derives from the kind of pluralism embodied in [F]. If forgiving is multiply realized by overcoming in each case different blaming emotions, plausible conditions for forgiving will tend to be necessarily limited in scope. If resentment is what I feel, then perhaps I should not forgive you unless you undergo some kind of punishment or atonement. But if my feelings are merely hurt for what you did, then maybe that would seem too harsh.

Another, perhaps deeper, reason goes back to what the emotions, and $a$ fortiori the blaming emotions, are. As argued above, to the extent that they are motivational states of a distinctive sort, emotions are holistically shaped. This means not only that which emotions one has depends on other motivational states. It also means that the kind of considerations that can potentially influence having 
(or not) a given emotion have what can be called "variable relevance." "That is, the things that count as good reasons to have (or not) a certain emotion in one context need not be good reasons to have (or not) that emotion in a different context.

Let us grant, as some have argued, that resentment is often a good response to being disrespected (Murphy \& Hampton 1988: 59-60). Still one can imagine cases in which the latter might not be a reason at all to feel resentful. If I antecedently believe (maybe for good reasons) that I deserve little respect, then disrespecting me might not give me a reason to resent. Perhaps, it might only give a reason to feel sad or helpless. Similarly, if someone breaks a promise made to me, I might be rightly angered at her. If, however, if I didn't care much for what she promised, I might simply let the whole thing slide.

The point, I think, extends to forgiveness. In some cases, your resolve to become a better person can be a good reason to put my disappointment behind. But in others, say, after repeated wrongdoing, a sudden resolve to change might even be a source of more disappointment. Why didn't you resolve to be better earlier? Did you really have to put me through this? Likewise, coming out clean is sometimes a reason to forgive someone. You normally appreciate being told the truth. Other times, however, it is a reason to be angered, say, if person comes clean just because the guilt is consuming her. "At least I told you the truth," sometimes hurts as much as the truth being told.

No doubt, there is the temptation to explain away the variability just noted here by hedging. It is not the resolve that disappoints, it is the timing of it; it is not the truth that angers, but that you told it just to get rid of the guilt. Yet, this kind of

"The phrase "variable relevance" is taken from Jonathan Dancy, who uses considerations similar to the ones raised here to argue for skepticism about the existence of moral principles (see, for Dancy 2017). The argument here is much weaker than that. The point is not that there are not any principles or plausible generalizations about forgiveness, only that there are no proper necessary conditions the offender needs to meet for forgiveness to happen. This style of argument is just a version of Donald Davidson's (1970) old argument for the holism of the mental to the absence of rationality norms (See McDowell 1985 and Child 1992 for discussion). 
hedging, rather than saving the intuition of there being necessary conditions of forgiveness, actually helps make the point here. What are, on occasions, good reasons to forgive give rise to appearance of there being conditions for forgiving (or not) because in stating them one takes for granted, often unwittingly, certain contextual particularities.

If this is true, then we have a principled explanation as to why no reason for forgiving (or not) can be turned into a condition of forgiveness. And if this is true, there too will be no reason for thinking that there are norms stating those conditions. "You ought not forgive unless the wrongdoer resolves to change in the right ways and at the right time; but, if for some reason she cannot change in that way, forgive only if she shows repentance for the right reasons and in the right amount; and if that does not hold, then..." is only by courtesy a norm. Conditional norms might have exceptions, but they cannot be as open ended as this.

Just to be clear, this is not to say that there are no good or bad episodes of forgiving: forgiving might be a rational process even if it is not always the most rational thing to do, say, if the responses that I take as reasons are themselves not rational. Nor is it to deny that some considerations are generally good reasons to forgive. It is, rather, to say that in the right circumstances any of these generalizations might cease to hold. Accordingly, one should be weary to build into one's account of forgiveness necessary conditions to forgive or not to do it. Much less, one should not see the failure to meet these conditions as indication that something is wrong with the forgiver..$^{15}$

\section{Ethics}

${ }^{15}$ One more caveat. In addition to norms stating conditions for forgiveness, other general norms might potentially apply to it. Dana Nelkin (2013), for instance, suggests that one must not forgive unless one thinks it is good thing to do it. I agree that such norm might exist. But notice that that norm should not necessarily be read as an ethical norm; it could be a norm of rationality. Consider a close analogue: one must not intend to do something, unless one thinks it is a good thing to do it. 
Forgiving seems to be a good thing. At the very least, certain common practices seem to presuppose that it is. Some of this appeal is explained by the benefits that forgiving others has. Even if forgiving does not involve a change in affect, the motivational change tends to be healthy: one ceases to ruminate, one can move on, etc. And, even if things do not go back to the way they used to be, forgiveness helps make social interactions, often inevitable, run more smoothly.

Many theorists have thought that there is more to the goodness of forgiving than consequentialist considerations can offer. In and of itself, they think, there is something good about it. There are various ways of developing this thought. On some conditional accounts, for instance, the goodness of forgiving comes from considerations of justice (Murphy \& Hampton 1998: 29-30). It would be unfair not to forgive someone who meets the conditions for forgiving. Unconditional accounts, by contrast, tend to emphasize the presence of general attitudes of good will in the forgiver: a spirit of generosity (Allais 2013), respect for humanity (Govier 1999), or human solidarity (Garrard \& McNaughton 2002).

Forgiveness, I have now argued, is a reasonable reaction to the responses that our blaming emotions evoke. I have offered some reasons for skepticism about there being necessary conditions of forgiving. Absent these conditions, a generalized concern with justice seems to float free. That is, in some cases, not forgiving might be unfair. But, in other cases, it might be morally speaking up to the victim whether she forgiveness or not. On the other hand, I do not think general attitudes of goodwill are necessary to forgive. Thinking that they are often puts unduly pressure on victims to forgive: "Come on. Be charitable," might be an innocent exhortation to reconsider, but it could also be a manipulative strategy. Is there, then, in my account any goodness left for forgiveness?

I believe that there is. Blaming, as I have insisted, is normally embedded in a social exchange. That is, it is incarnated in emotions that characteristically motivate us to act in socially meaningful ways, and that potentially generate responses in others. This means that the reasons to forgive can come from a combination of features of the social environment in which the wrongdoing happens. Sometimes, it comes from my disappointment followed by your feeling sad about it, or your resentment alerting me that I need to repair. Other times it results from the 
apology you asked from the victim after noticing my indignation. I might even forgive myself moved by the love and affection with which you responded to my awful guilt.

If this is right, then whatever is inherently good about forgiving need not be something morally good. It can, for lack of a better word, be something socially good. From the perspective of the person who forgives, forgiving shows (at least in the cases considered here) a reasonable attunement to the responses of others: their guilt, their resolve to change, their desire that things had been different, etc. From a more social perspective, episodes of forgiveness (as those described here) show a shared responsiveness to the each other emotional lives and motivations. These might not be personal or communal moral virtues. But they certainly are social virtues.

Obviously, it is hard to say what makes something social and yet not moral. But, for present purposes, one can look at the contrast in this way. The kind of attunement and responsiveness that makes forgiving possible requires being able to read the mind of those people with whom we interact and being interested in doing it. But these mind reading abilities fall short of anything close to empathy. To be attuned to others, to properly respond to their addresses, is more a social skill than anything else. It does not require the ability to put yourself in their shoes, to understand where they are coming from, etc.. Certainly, it is not an exercise in compassion or pity (But see Novitz 1998 for a view of forgiveness that requires these things).

This, perhaps, explains why sometimes it is hard for forgiveness to come by, especially after long periods of relationship estrangement. It is not that one of the parties lacks some morally good quality-although that is possible, say, if someone is excessively vindictive. It is not that each party has a different appreciation of how each deserves to be treated-although that too can happen. It is rather that, as the relationship deteriorates, one becomes less able to read the other person's responses, how she is feeling about oneself, what her motivations are. Absent this kind of uptake, one is normally left with the offense and thoughts of how things used to be.

\section{Conclusion}


I began with an often-mentioned "puzzle" concerning forgiveness. Standard solutions to the puzzle consists in arguing that forgiveness (at least, of the rational kind) involves a change in judgment—only that the judgment is not one regarding the culpability of the wrongdoer. Here, I have shown why such a change in judgment is not necessary. The argument develops a model of rational forgiveness based on the idea that forgiveness is a social and public form of emotional distancing. In the end, I've discussed some advantages that follow from thinking that the better reasons for forgiving others often reside in the way they react to the emotions with which we blame them. ${ }^{\text {ta }}$

\section{References}

Adams, M. M. (1991). Forgiveness: A Christian Model. Faith and Philosophy ,8 (3), 277-304.

Allais, L. (2008). Wiping the Slate Clean: The Heart of Forgiveness. Philosophy \& Public Affairs, 36 (1), 33-68.

Allais, L. (2013). Elective Forgiveness. International Journal of Philosophical Studie,s 21(5), 637-653.

Bartlett, M. \& DeSteno, D. (2006). Gratitude and Prosocial Behavior: Helping When It Costs You. Psychological Science, 17 (4), 319-25.

Baumeister, R.E., Exline, J.J., \& Sommer, K.L. (1998). The Victim role, Grudge Theory, and two Dimensions of Forgiveness. In E.L. Worthington, Jr. (Ed.),

${ }^{16}$ This paper benefited from comments and criticisms by audiences at the Moral Responsibility Workshop hosted by the University of Arizona, the Universidad de Antioquia, and the philosophy colloquium at Universidad de los Andes. I am specially thankful to Elinor Mason and Michael McKenna, who provided written comments that helped me see better what I wanted to say and sharpen my ways of saying it. 
Dimensions of forgiveness (pp. 79-104). Philadelphia: Templeton Foundation Press.

Bennett, C. (2003). Personal and Redemptive Forgiveness. European Journal of Philosophy, 11 (2), 127-144.

Child, W. (1992) Anomalism, Uncodifiability and Psychophysical Relations. Philosophical Review, 102(2), 215-245.

Davidson, D. (1970) Mental Evens. In Actions, Reasons, and Causes. Oxford: Clarendon Press.

D'Arms, J. and Jacobson, D. (2003). The Significance of Recalcitrant Emotions; Or Anti- Quasijudgmentalism. Royal Institute of Philosophy Supplement, 52, 127-145.

Damasio, A. (1999). The Feeling of What Happens: Body and Emotion in the Making of Consciousness. San Diego (California): Harcourt Trade.

Dancy, (2017). Moral Particularism. The Stanford Encyclopedia of Philosophy (Winter 2017 Edition), Edward N. Zalta (ed.), forthcoming URL = $<$ https:/ / plato.stanford.edu/archives/win2017/entries/moral-particularism/>.

Debus, D. (2007). Being Emotional about the Past: on the Nature and Role of Pastdirected Emotions. Nô̂s, 41, 758-779.

Fincham, F. (2000). The Kiss of the Porcupines. From Attributing Responsibility to Forgiving. Personal Relationships, 7, 1-23.

Fricker, M. (2016). What's the Point of Blame? A Paradigm Based Explanation. Noûs, 50 (1),165-183.

Fricker, M. (forthcoming). Forgiveness: Its Powers and Corruptions.

Frijda, N. H. (2008). The Psychologists' Point of View. In M. Lewis, J. M. HavilandJones, L. F. Barrett (Eds.), Handbook of Emotions (3rd edn., pp. 68-87). New York: Guilford Press.

Garrard, E. \& McNaughton, D. (2002). In Defense of Unconditional Forgiveness. Proceedings of the Aristotelian Society, 103: 39-60. 
Gormley, S. (2014). The Impossible Demand of Forgiveness. International Journal of Philosophical Studies, 22 (1), 27-48.

Grzankowski, A. (2017). The Real Trouble with Recalcitrant Emotions. Erkenntnis, 82 (3), 641-651.

Griswold, C. (2007). Forgiveness. A Philosophical Exploration. Cambridge University Press.

Govier, T. (1999). Forgiveness and the Unforgivable. American Philosophical Quarterly, 36 (1), $59-75$.

Haber, J. G. (1991). Forgiveness. Lanham: Rowman and Littlefield.

Helm, B. (2001). Emotional Reason. New York: Cambridge University Press.

Hieronymi, P. (2001). Articulaing an Uncompromising Forgiveness. Philosophy and Phenomenological Research, 62 (3), 529-555.

Holmgren, M. R. (2012). Forgiveness and Retribution: Responding to Wrongdoing, Cambridge: Cambridge University Press.

Kearns, J., Fincham, F. (2004). A Prototype Analysis of Forgiveness. Personality and Social Psychology Bulletin, 30(7), 838-855.

Kolnai, A. (1973). Forgiveness. Proceedings of the Aristotelian Society, 74: 91-106.

Lawler-Row, K., Scott, C., Raines, R., Edlis-Matityahou, M., \& Moore, E. (2007). The varieties of forgiveness experience: Working toward a comprehensive definition of forgiveness. Journal of Religion and Health, 46(2), 233-248.

Lazarus, R. (1991). Emotion and Adaptation. New York: Oxford University Press.

Linden, M., Baumann, K., Rotter, M., \& Schippan, B. (2007). The Psychopathology of Posttraumatic Embitterment Disorders. Psychopathology, 40, 159-165.

Macnamara, C. (2015). Blame, Communication, and Morally Responsible Agency. In R. Clarke, M. McKenna \& A. Smith (eds.), The Nature of Moral Responsibility: New Essays (pp. 211-236). New York: Oxford University Press. 
McCullough, M., \& vanOyen, C. (2001). The Psychology of Forgiveness. In C.R.

Snyder \& S. J. Lopez (Eds.), Handbook of Positive Psychology (pp. 446-458).

Oxford: Oxford Psychology Press.

McDowell, J. (1985) Functionalism and Anomalous Monism. In Mind, Value, and Reality. Cambridge: Harvard University Press.

McGeer, V. (2010). Co-reactive attitudes and the making of moral community. En C. MacKenzie, R. Langdon (Eds.). Emotions, Imagination, and Moral Reasoning (pp. 299-326). New York: Taylor and Francis.

McKenna, M. (2012). Conversation and Responsibility. New York: Oxford University Press.

Murphy, J. \& Hampton, J. (1988). Forgiveness and Resentment, Forgiveness and Mercy. Cambridge University Press.

Murphy, J. (2012). Punishment and the Moral Emotions: Essays in Law, Morality, and Religion. New York: Oxford University Press.

Nelkin, D. (2013). Freedom and Forgiveness. In I. Haji \& J. Caoette (Eds.), Free Will and Moral Responsibility, Newcastle upon Tyne: Cambridge Scholars Press.

Norlock, K. (2008). Forgiveness from a Feminist Perspective. Lexington Books.

Novitz, D. (1998). Forgiveness and Self-respect. Philosophy and Phenomenological Research, 58 (2), 209-315.

Nussbaum, M. (1997.) Emotions as judgments of value and importance. In P. Bilimoria y J. Mohanty (Eds.), Relativism, Suffering and Beyond (pp. 271-283). New Dehli: Oxford University Press.

Nussbaum, M. (2016). Anger and Forgiveness: Resentment, Generosity, and Justice. New York: Oxford University Press.

Owen, G. E. L. (1960) Logic and Metaphysics in Some Earlier Works of Aristotle. In I. During and G. E. L. Owen (eds.) Plato and Aristotle in the Mid-Fourth Century, (163-190) Göteborg: Almquist and Wiksell. 
Prinz, J. J. (2004). Gut Reactions. New York: Oxford University Press.

Roberts, R. C. (1995). Forgivingness. American Philosophical Quarterly, 32 (4), 289 306.

Scarantino, A. (2014) The motivational theory of emotions. En J. D'Arms, D. Jacobson, Moral Psychology and Human Agency (pp. 156-157), Oxford: Oxford University Press.

Shoemaker, D. and Vargas, M. (forthcoming). Moral Torch Fishing:A Signaling Theory of Blame.

Strawson, P. F. (1982). Freedom and Resentmeent. Freedom and Resentment and Other Essays. Londres y Nueva York: Routledge.

Tappolet, C. (2016). Emotions, Values, and Agency. New York: Oxford University Press.

Wallace, J. (1994). Responsibility and the Moral Sentiments. Cambridge, Mass.: Harvard University Press.

Warmke, B., \& McKenna, M. (2013). Moral Responsibility, Forgiveness and Conversation. In I. Haji, \& J. Caouette (Eds.), Free Will and Moral Responsibility (pp.189-212). Newcastle upon Tyne: Cambridge Scholars Publishing.

Wolff, S. (2011). Blame, Italian Style. In R. J. Wallace, R. Kumar, \& S. Freeman, Reasons and Recognition: Essays on the Philosophy of T.M. Scanlon (pp. 332-347). New York: Oxford University Press.

Zaibert, L. (2009). The Paradox of Forgiveness. Journal of Moral Philosophy, 6, 365393.

Znoj, H. (2011). Embitterment-a larger perspective on a forgotten emotion. Embitterment (pp. 5-16). Vienna: Springer. 